\title{
The Centro Internazionale Radio Medico Symposium "The Way Forward of Maritime Telemedicine"
}

\author{
Francesco Amenta $^{1,2}$ \\ ${ }^{1}$ Telemedicine and Telepharmacy Centre, University of Camerino, Camerino, Italy \\ ${ }^{2}$ Research Department, International Radiomedical Centre (CIRM), Rome, Italy
}

In 2015 the Centro Internazionale Radio Medico (CIRM) has celebrated his $80^{\text {th }}$ anniversary. In fact the Centre, developed by the initiative of Guglielmo Marconi who proposed the use of radio to assist remote patients that cannot be reached in a reasonable elapse of time by a health practitioner, started his activity in 1935.

CIRM established by the Italian government as the Italian Telemedical Maritime Assistance Service (TMAS) provides free medical assistance to ships without a doctor on board. In the 80 years of his activity CIRM has assisted approximately 70,000 patients on board ships of any nationality sailing in all the seas of the world. These figures make CIRM as the TMAS with the largest experience worldwide of medical assistance to people on board of seagoing vessels.

For celebrating from a scientific point of view our $80^{\text {th }}$ anniversary the Centre has organised in Rome a Symposium entitled "The Way Forward for Maritime Telemedicine". The purpose of the meeting held at CIRM on October 30 and 31,2015 , was to discuss the status of telemedical assis- tance delivered to seafarers and to identify new, future developments for it.

The scientific program of the Symposium has included the topics listed below:

- TMAS worldwide: census and survey on organisation and activities;

- common systems for recording cases assisted by TMAS;

- technology for improving quality of on board medical care;

- new experiences.

Authors of 10 papers presented at the Symposium were requested to provide a full-length manuscript. These manuscripts were collected and will be published in two issues of "International Maritime Health" for editorial reasons.

I should to thank the Editors of "International Maritime Health" for the opportunity to publish the main contributions to the CIRM Symposium in their journal. The collaboration of Mr Antonio Arcese for the organisation of the secretariat of the Symposium and of Mr Raffaele Della Medaglia for the organisation of meeting sessions is gratefully acknowledged. 